\title{
SEISMIC REFLECTION IMAGING OF THIN, KIMBERLITE DYKES AND SILLS: EXPLORATION AND DEPOSIT CHARACTERIZATION OF THE SNAP LAKE DYKE, CANADA
}

\author{
Philip Hammer, Kumar Ramachandran and Ron Clowes \\ Department of Earth and Ocean Sciences, University of British Columbia, Canada
}

\section{INTRODUCTION}

Seismic reflection techniques have not been frequently utilized by the diamond exploration and mining industry because of the primary focus on near-vertical kimberlite pipes. For these structures, airborne magnetic and electromagnetic surveys represent costeffective methods of detection. However, potential field techniques are unlikely to reveal thin, sub-horizontal, kimberlite dykes and sills. As a result, these structures are likely to be overlooked and are not well understood, although they may prove to be both numerous and valuable. Since seismic reflection techniques are especially well suited for mapping subhorizontal structures, dykes and sills have the potential to be excellent seismic targets.

One example of a diamondiferous dyke is the Snap Lake kimberlite dyke in Canada's Northwest Territories (Figure 1). Described in more detail by McBean et al. (2003), the gross geometry and structure of the deposit has been defined by a substantial drilling program. The 2-3 m thick dyke forms a gently dipping $\left(\sim 20^{\circ}\right)$ sheet that plunges to more than $1300 \mathrm{~m}$ depth and extends over approximately $25 \mathrm{~km}^{2}$ (Figure 1). Investigations continue in order to obtain more detailed structural data for mine planning and to better understand how the dyke was emplaced. Drilling has obvious limitations in spatial sampling and the costs are extremely high in this environment. This is partially due to the target depth and properties of the granitic and metavolcanic host rock, but is exacerbated by the remote and logistically challenging location. For this pilot experiment, approximately $6 \mathrm{~km}$ of continuous $2 \mathrm{D}$ seismic data were obtained for the same cost as two $1000 \mathrm{~m}$ drill holes (D. Clarke, pers. commun., 2003). Therefore, to guide and minimize drilling programs, seismic reflection was considered as a potential tool for exploration purposes and for mapping characteristics (e.g., extent, continuity, and thickness) of known dykes.

In collaboration with De Beers Canada Mining Inc. and Diamondex Resources Ltd., a feasibility study and a subsequent 2-D reflection survey over the Snap Lake dyke were carried out to provide information locally useful to the companies involved and to address two general questions. First, is the seismic reflection method an effective and cost-efficient exploration tool for shallow-dipping kimberlite dykes and sills in a hardrock environment? Secondly, can seismic reflection studies image the kimberlite body and related geology at scales that would prove useful for mine planning and development? The ability to ground-truth seismic results with drill hole data makes the Snap Lake dyke a unique opportunity to test seismic reflection techniques on thin kimberlite structures.

\section{SNAP LAKE DYKE: STRUCTURE AND GEOLOGIC SETTING}

Snap Lake is located within the Slave Province (NWT, Canada), one of the principal Archean components of the North American craton. The Snap Lake dyke was emplaced about $100 \mathrm{~km}$ south of the main kimberlite field in the Lac de Gras region. There are three primary geological units (Figure 1). The dominant intrusives belong to the Defeat pluton suite (2610-2590 Ma) and comprise granodiorite, tonalite and monzogranite with abundant muscovite-bearing pegmatite locally. The metavolcanic rocks are layered amphibolites that represent intensely flattened mafic metavolcanics and gabbroic intrusions. The supracrustals are primarily high-grade metaturbidites and migmatite. Proterozoic diabase dykes dissect the study area. The Snap Lake dyke is hypabyssal kimberlite with a high proportion of coarse-grained macrocysts (3-10 mm) (Kirkley, 2001). Based on drill core data, the Snap Lake dyke dips to the northeast $\left(5-30^{\circ}\right.$, see Figure 2), gradually twisting toward a northward dip. The dyke thickness is variable; along the seismic profiles, drill cores return kimberlite thicknesses from $3.4 \mathrm{~m}$ to less than $1 \mathrm{~m}$. Below $1000 \mathrm{~m}$, the few intersections of the dyke yield cores of less than $1.6 \mathrm{~m}$ in thickness. In addition to variability in thickness, the drill intersections indicate that the dyke is complex in form, occasionally feathering into multiple strands or rapidly changing dip. The drill cores also show that the dyke is accompanied by related intrusions, fracturing and alteration in the adjacent host rock (M. Kirkley, pers. commun., 2002). More detailed 
information about the dyke composition and thickness can be found in McBean (2003).

\section{FEASIBILITY STUDY}

Imaging thin kimberlite dykes and sills at depths exceeding $1 \mathrm{~km}$ is challenging for two reasons. First,

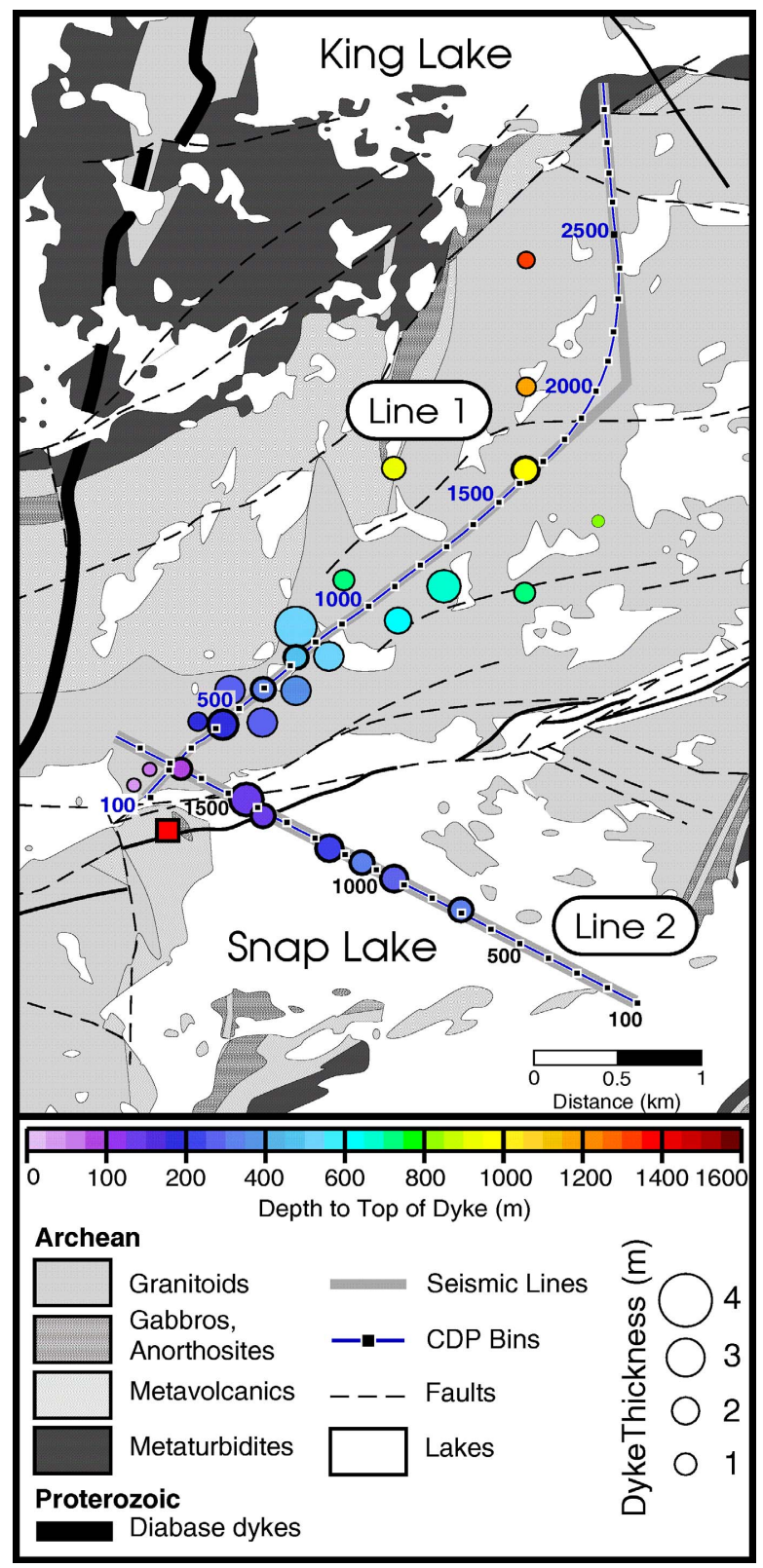

Figure 1. Seismic line locations on a simplified geological map (courtesy of De Beers Canada Mining Inc.). Drillhole locations closest to the seismic lines are noted. Intersection depth is colour-coded and dyke thickness is given by circle diameter. CDP bin centers are also labeled for comparison with Figure 2. Axes are in northings and eastings in metres. resolving or detecting a 1-3 m-thick structure requires unusually high frequencies $(>200 \mathrm{~Hz})$ for imaging such a deep target. Second, guidance from other seismic reflection surveys of kimberlite dykes is extremely limited; no comparable exploration-scale seismic surveys of thin kimberlite dykes have been reported. Working on a thicker target, Gendzwill and Matieshin (1996) successfully used seismic reflection techniques to identify the top of a 100 m-thick extrusive kimberlite lens (crater facies) buried beneath approximately $100 \mathrm{~m}$ of sedimentary cover. The few published engineeringscale surveys carried out on shallow $(<100 \mathrm{~m})$ dykes have had only limited success (e.g., Hearst, 1998). Thin bed exploration for coal seams and petroleum reservoirs is successful but there are significant differences between detecting these targets in a sedimentary environment and imaging kimberlites in an igneous host rock setting. Therefore, physical properties measurements and a modelling study were carried out to evaluate the feasibility of a seismic reflection survey proposed for the Snap Lake dyke.

The physical properties of the kimberlite dykes and the host rocks determine the impedance contrasts detected by a seismic experiment. In addition to using published data (e.g., Ji et al., 2002), compressional (P) velocity and density measurements were made on drill core samples from Snap Lake (D. Schmidt, U. Alberta, 2001). P-wave velocities were determined from standard pressure to $300 \mathrm{MPa}(\sim 10 \mathrm{~km}$ depth $)$ at room temperatures; density measurements were made at standard pressure and temperature. The kimberlite samples exhibit significantly lower P-velocities (average $4.3 \pm 0.1 \mathrm{~km} / \mathrm{s}$ at $50 \mathrm{MPa}$ ) than those measured in the host rock (average $5.6 \pm 0.2 \mathrm{~km} / \mathrm{s}$ at $50 \mathrm{MPa}$ ). Their densities (average $2.44 \pm 0.04 \quad \mathrm{~g} / \mathrm{cm}^{3}$ ) are consistently lower than those of the host rocks (average $2.95 \pm 0.03 \mathrm{~g} / \mathrm{cm}^{3}$ and $2.66 \pm 0.03 \mathrm{~g} / \mathrm{cm}^{3}$ ). Thus, the impedance contrast between the kimberlite and host rocks is large $(\sim 0.2)$; significant reflected energy should be generated.

Despite the large impedance contrast, resolving the top and bottom surfaces of the dyke requires frequencies of at least $500 \mathrm{~Hz}$, so high the energy is rapidly attenuated with depth. However, the dyke can be detected with lower frequencies and thin-bed tuning effects can enhance detection. Theoretical modelling to test the seismic response of thin kimberlites demonstrated the feasibility of the proposed survey and provided insight for planning the acquisition geometry. The main conclusions of the study are:

1) At depths to $500 \mathrm{~m}$, sufficient $200-400 \mathrm{~Hz}$ energy is returned that the likelihood of detecting a $1 \mathrm{~m}$ 
thick kimberlite dyke is high. As target depths approach $1000 \mathrm{~m}$, weak amplitudes due to attenuation increase risk substantially. At all depths, care is required to maximize signal-to-noise ratios during acquisition (e.g., recording data with high fold and ensuring excellent source and receiver coupling). During processing, accurate statics corrections must be made for variations in topography and near-surface velocities.

2) Recording to large offsets $(>1000 \mathrm{~m})$ can yield useful reflection amplitudes for imaging the dyke at depths greater than $500 \mathrm{~m}$. In addition, longer offsets yield data uncontaminated by the significant ground roll generated by the till and shallow water/ice along the line.

3) Dyke thickness is unlikely to be resolved except perhaps where the Snap Lake dyke is thickest.

4) With an acquisition layout designed for target detection to more than $1 \mathrm{~km}$ depth, small variations in the topography of the dyke, (e.g., 5 m over a 100 $\mathrm{m}$ distance at $300 \mathrm{~m}$ depth) will be difficult to document. Large gaps $(>20 \mathrm{~m})$ in the continuity of the dykes should be detectable but moderate noise levels and 3-d effects will likely mask smaller variations in continuity. Feathering of dykes will only be detected through variations in amplitude.

\section{DATA ACQUISITION}

The data acquisition layout was designed to achieve multiple goals. In addition to simply imaging the dyke, the survey was to determine the optimal acquisition parameters for potential future surveys. Therefore, the survey included explosive and vibroseis sources, land and lake-ice coverage, and long offsets. Data were acquired in May 2001 along two lines (Figure 1). Line $1(5.86 \mathrm{~km})$ ran down-dip to the northeast, turning to the north after $3.94 \mathrm{~km}$. The line was positioned almost entirely on land. Line $2(3.46 \mathrm{~km})$ was oriented approximately cross-dip with the majority of the profile $(2.86 \mathrm{~km})$ crossing Snap Lake. Water depth reached a maximum of $15 \mathrm{~m}$ beneath the line and ice thickness was approximately $1 \mathrm{~m}$ during acquisition.

The basic acquisition configuration was the same for both explosive and vibroseis lines. Data were recorded on an I/O System 2000. Hardware limitations restricted the maximum array size to 816 phones $(28 \mathrm{~Hz})$ when sampled at $0.5 \mathrm{~ms}$. To provide improved spatial sampling at the shallow end of the dyke, geophones were spaced at $2 \mathrm{~m}$ intervals along the SW $1.94 \mathrm{~km}$ of Line 1 (Figure 1). An asymmetric spread was deployed along Line 1 (down-dip) while a symmetric layout was used along Line 2 (cross-dip).

In order to generate sufficient energy at the high frequencies required, small explosive shots detonated in holes drilled through the glacial till into bedrock were considered the optimal choice. However, drilling numerous shot holes in a granitic environment is costly and can be accompanied by permitting difficulties. A vibroseis unit is cost-efficient, more easily permitted, and able to operate on both lake ice and land. However, it was unclear if the poorer coupling associated with a mini-vibe would limit the high frequency energy produced. Therefore, both sources were tested. Along Line 1,460 shots $(0.25 \mathrm{~kg}$ of Pentalite, drilled $1-3 \mathrm{~m}$ into bedrock) were detonated at nominal $8 \mathrm{~m}$ intervals. Fold ranged from 40 to 260. Line 2 included 222 vibroseis source points, again at $8 \mathrm{~m}$ shot intervals. Eight vibroseis sweeps to $500 \mathrm{~Hz}$ were stacked for each shot point. Although much reduced from the initial survey plan, a direct comparison of explosive and vibroseis sources was achieved along a small portion of Line 2 where 23 Pentalite shots were recorded in addition to the vibroseis data.

\section{DATA PROCESSING}

A relatively standard data processing flow was used but to enhance the chances of imaging the thin target, considerable effort was taken with statics corrections (refraction and residual) as well as velocity and spectral analyses. The initial processing steps included field geometry, quality control (trace editing and muting), and first-break picking. Prestack processing included refraction statics, band-pass filtering $(120-450 \mathrm{~Hz}), f-k$ filtering, spherical divergence, spectral balancing, NMO, deconvolution, and residual statics. Poststack processing included deconvolution, time-variant filtering, and finite difference time migration.

\section{RESULTS}

Reflections from the dyke were detected along both lines. The Line 1 land profile was spectacularly successful while difficulties posed by data acquisition on ice limited data quality along Line 2.

\section{LINE 1: EXPLOSIVE SOURCES ON LAND}

The dyke is superbly imaged (Figure 2) from $30 \mathrm{~ms}$ $(\sim 70 \mathrm{~m})$ to $425 \mathrm{~ms}(\sim 1300 \mathrm{~m})$ with faint reflections continuing to at least $520 \mathrm{~ms}(1650 \mathrm{~m})$. The coincident and near-coincident drillhole data correlate well with 
the reflection image, but the seismic profile adds considerable detail to the known dyke topography.

The frequency content of the dyke reflections in the data was 240-350 Hz; dominant frequencies generally decreased with reflector depth due to attenuation. Throughout most of the stacked profile, the reflective package comprises $3-4$ cycles $(\sim 20 \mathrm{~ms}$ or $\sim 90 \mathrm{~m})$ in both shot gathers and stacked sections (Figure 2). As expected, the dyke thickness is not resolved. Several factors likely contribute to the exaggerated thickness and reduced frequencies of the reflection package along the profile. Multiples from internal reflections within the dyke, as well as those trapped within thin, intermittent till layer are modelled to have significant potential effects. The thickness of the $2 \mathrm{D}$ reflection package is also increased by $3 \mathrm{D}$ complexity of the dyke

SW
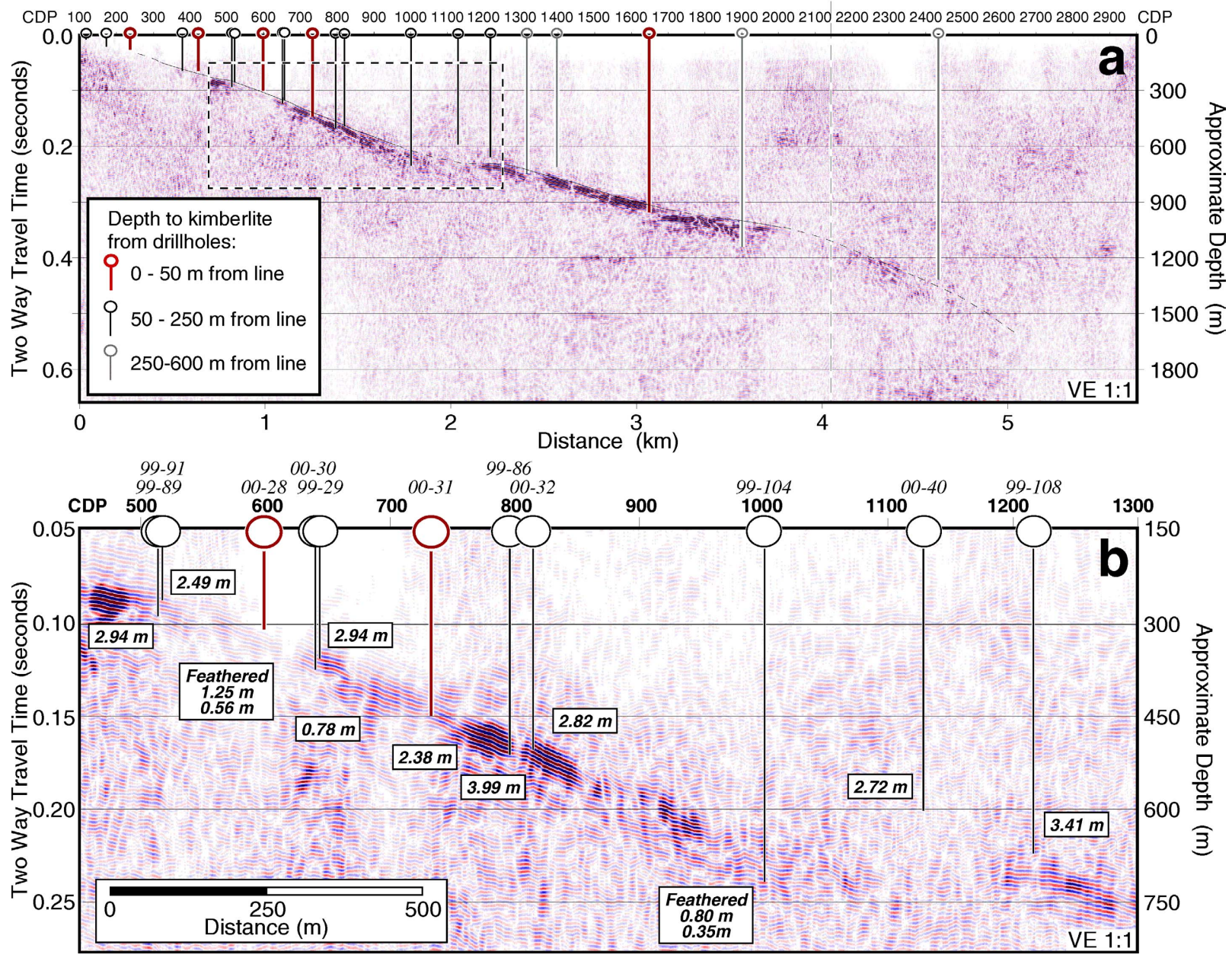

Figure 2. a) Unmigrated stack of Line 1. Thin black line traces top of dyke reflections. b) Enlargement of boxed area in (a). Migrated stack imaging the dyke through a zone with significant variations in reflector amplitude and dip. Depths to kimberlite from nearby drillholes are indicated. In (b), dyke thickness is labelled for each drillhole. For cores exhibiting significant feathering, the thickest kimberlite intersections are labelled. Note the correspondence between zones of low amplitude with regions that are feathered or have significant cross-dip. Approximate depths calculated assuming $6 \mathrm{~km} / \mathrm{s}$ and are corrected to a $465 \mathrm{~m}$ datum.

structure (topography, thickness, dip). In addition, the drill cores indicate considerable variability in the degree of feathering, small intrusions (dykelets), alteration and fracturing adjacent to the dyke. Furthermore, imperfect statics corrections could also help reduce the stacked frequencies and increase the effective seismic thickness of the dyke.

There are considerable amplitude variations along the dyke reflector. Attributing these variations to specific dyke structure is difficult because all of the factors that influence the thickness of the reflection package can also influence amplitudes. However, two important observations can be made.

1) Several zones where reflection amplitudes drop and continuity decrease correspond to places where drillcores indicate the dyke changes from a NE S

$\mathrm{N}$

然

.


relatively simple planar sheet to a region with considerable $3 \mathrm{D}$ variation in topography and thickness (e.g., CDP ranges 500-700 and 850-1250 in Figure 2).

2) Amplitudes decrease significantly below $0.35 \mathrm{~s}$ $(\sim 1150 \mathrm{~m})$. The few drill cores from these depths indicate the dyke thins to less than $1.6-1.0 \mathrm{~m}$. Similarly, reduced amplitudes are observed in other regions associated with dyke thicknesses of less than $1.3 \mathrm{~m}$. At the frequencies involved in this experiment, tuning effects may be reduced as dyke thickness decreases below $1.6 \mathrm{~m}$.

The long offset data were important for imaging the dyke at depth. Tests using selected offset ranges indicate that, for exploration purposes, thin dyke detection below $400 \mathrm{~m}$ improved significantly as offsets were increased to $1000 \mathrm{~m}$. When the target depth exceeded $1000 \mathrm{~m}$, slight improvements were observed using offsets exceeding $1000 \mathrm{~m}$.

\section{LINE 2: VIBROSEIS ON LAKE ICE AND LAND}

In contrast with the superb reflection data acquired along Line 1, the Line 2 vibroseis dataset was decidedly inferior. The reverberations and flexural wave energy generated by the Snap Lake ice, water, and till layers contaminated the data with noise that proved difficult to remove. Furthermore, high frequencies were attenuated, effectively lowering the high end of the frequency spectrum and thereby decreasing the resolving and detection potential of the dataset. Although the majority of Line 2 crossed Snap Lake, the northwest $600 \mathrm{~m}$ of the line were on land; the vibroseis source successfully imaged the dyke (60-300 m depth) along this part of the profile. The dyke was not imaged beneath the lake ice.

\section{SUMMARY}

The Snap Lake seismic experiment demonstrated that seismic reflection can be an extremely useful tool for exploration and deposit mapping of thin, kimberlite dykes or sills. With an appropriate target, drilling programs that are limited by high costs and poor spatial sampling could be significantly enhanced by the addition of seismic reflection profiles. As an exploration-scale tool for thin dyke detection, the bedrock-coupled, dynamite data excelled. The limited success of the land-based vibroseis data indicated that a vibroseis source could also produce acceptable results. Indeed, a subsequent survey clearly imaged the dyke to over $1400 \mathrm{~m}$ depth using a vibroseis source (Diamondex Resources Ltd., pers. commun., 2002). Unfortunately, the failure of the lake-ice vibroseis line is a significant, if not unexpected, outcome because 30$40 \%$ of the Slave kimberlite zone is covered by water. Winter surveys have many advantages in this region as environmental permitting is difficult due to the fragile terrain and sensitive lake ecosystems. In addition, mobility is easy when the terrain is covered by snow and ice. Alternative techniques to working over the lakes must be used.

The survey acquisition parameters and dyke thickness limited the usefulness of the data for mine planning. Dyke thickness was not directly resolved and 3-D structure makes interpretation of fine-scale structure and continuity difficult. However, this initial application of seismic techniques has raised a number of issues that if addressed, suggest that reflection data may be even more useful for deposit characterization and more detailed mine development applications. Ongoing work is investigating correlations between the variability in reflection attributes with tuning response, dyke thickness and physical properties within and adjacent to the dyke (e.g., McBean et al., 2003).

\section{REFERENCES}

Hearst, R.B. 1998. Reflections on kimberlite: a seismic adventure: 68th Ann. Internat. Mtg., Soc. Expl. Geophys., Expanded Abstracts, Min 2.4.

Gendzwill, D.J., Matieshin, S.D., 1996. Seismic reflection survey of a kimberlite intrusion in the Fort à la Corne district, Saskatchewan. In: LeCheminant, A.N., Richardson, D.G., Dilabio, R, and Richardson, K.A. (Eds.), Searching for diamonds in Canada: Geological Survey of Canada Open File Report 3228, 251-253.

Ji, S., Wang, Q., Xia, B., 2002. Handbook of seismic properties of minerals, rocks and ores: Polytechnic International Press, Montreal.

Kirkley, M., 2001. The Snap Lake kimberlite dyke of the Slave province: comparisons and contrasts with Kaapvaal kimberlite dykes. In: Abstracts of the SlaveKaapvaal workshop, Merrickville, Canada.

McBean, D., Kirkley, M., Revering, C., 2003. Structural controls on the morphology of the Snap Lake kimberlite dyke. In: Proceedings of the 8th International Kimberlite Conference, Victoria.

Mitchell, R.H. 1986. Kimberlites: Mineralogy, Geochemistry and Petrology. Plenum Press, New York and London.

Contact: PTC Hammer, University of British Columbia,

Earth and Ocean Sciences, 6339 Stores Road, Vancouver, BC, Canada, V6T 1Z4, E-mail: hammer@eos.ubc.ca 